REVIEW ARTICLE

H. Zacharatos

A.E. Hassan

A.I. Qureshi

\title{
Intravascular Ultrasound: Principles and Cerebrovascular Applications
}

\begin{abstract}
SUMMARY: Intravascular sonography is a valuable tool for the morphologic assessment of coronary atherosclerosis and the effect of pharmacologic and nonpharmacologic interventions on the progression or stabilization of atherosclerosis. An analysis of the different modes, applications, and limitations is provided on the basis of review of existing data from multiple clinical case studies, trials, and mechanistic studies. Intravascular sonography has been used to assess the outcomes of different percutaneous interventions, including angioplasty and stent implantation, and to provide detailed characterization of atherosclerotic lesions, aneurysms, and dissections within the cerebrovascular circulation. Evolution of intravascular sonographic technology has led to the development of more sophisticated diagnostic tools such as color-flow, virtual histology, and integrated backscatter intravascular sonography. The technologic advancement in intravascular sonography has the potential of providing more accurate information prior, during, and after a medical or endovascular intervention. Continued assessment of this diagnostic technique in both the intracranial and extracranial circulation will lead to increased use in clinical practice with the intent to improve outcomes.
\end{abstract}

ABBREVIATIONS: $\mathrm{Cl}=$ confidence interval; $\mathrm{EEL}=$ external elastic lamina; O.D. $=$ outer diameter
C urrently there are 3 types of sonography used to assess the extracranial and the intracranial circulation: 1) transcranial Doppler, 2) B-mode sonography, and 3) intravascular sonography (Table). The morphologic appearance of the intra-arterial and intravenous circulation can now be visualized by using intravascular sonography, which has become a commonly used diagnostic technique for randomized clinical trials assessing coronary plaque progression and regression. ${ }^{1}$ With excellent resolution, intravascular sonography provides cross-sectional images of both the arterial wall and lumen and identifies intimal flaps and irregularities, and the composition and extent of the atherosclerotic plaque. ${ }^{2-6}$ Evolution of the intravascular sonography technology has led to the development of more sophisticated diagnostic tools such as colorflow, virtual histology, and integrated backscatter intravascular sonography. ${ }^{7}$ The successful application of conventional (gray-scale) intravascular sonography in the coronary arteries has led to its application within the extracranial and intracranial arteries. Recently, intravascular sonography has also been used to identify and characterize carotid artery aneurysm, dissection, and thrombus. ${ }^{8}$

Intravascular sonography has been used successfully to assist in making measurements before and after percutaneous transluminal balloon angioplasty and stent placement, with emphasis on the identification of stent underexpansion, poor apposition, subacute stent thrombosis, and plaque protrusion. ${ }^{9,10}$ Real-time dynamic intravascular sonography of the cervical common carotid artery and internal carotid artery can detect defects that are not readily apparent by conventional angiography, such as residual stenosis, suboptimal plaque

From Zeenat Qureshi Stroke Research Center, the Departments of Neurology, Neurosurgery, and Radiology, University of Minnesota, Minneapolis, Minnesota.

Please address correspondence to Adnan I. Qureshi, MD, Departments of Neurology, Neurosurgery, and Radiology, University of Minnesota, 420 Delaware St SE, MMC 295, Minneapolis, MN 55455; e-mail: aiqureshi@hotmail.com

Indicates open access to non-subscribers at www.ajnr.org

DOI 10.3174/ajnr.A1810 coverage, arterial dissection, poor wall apposition of the stent, superficial calcification, atherosclerotic plaque progression or regression, and plaque ulceration. ${ }^{11-13}$ The sensitivity and specificity of intravenous sonography is higher than those of angiography and MR imaging for studying the vessel lumen diameter and characteristics. ${ }^{14,15}$ High extracranial carotid artery lesions are best evaluated with intravascular sonography because they are not well visualized with conventional noninvasive sonography. ${ }^{16}$ The growth of endovascular practices and intravascular sonography capabilities has set the stage for broader use of this technology in neuroendovascular procedures across the United States (Fig 1).

\section{Conventional Gray-Scale Intravascular Sonography}

The intensity of reflected signals that are collected by the intravascular sonographic transducer enables the creation of conventional gray-scale images. ${ }^{7}$ The elastin and collagen organization within the arterial wall provides the substrate that leads to different sonographic scattering properties between the individual layers. Sonography presents the intima (inner layer) as a white (hyperechoic) signal and the media as a dark (hypoechoic) and echolucent signal. The surrounding adventitia, the outermost layer, produces a white (hyperechoic) signal. The arterial wall of the normal elastic arteries typically has a homogeneous appearance when imaged by intravascular sonography, secondary to the elastin in the media. Hypoechoic (dark) media are seen when muscular arteries are visualized, due to the presence of arterial smooth muscle cells (Fig 2). ${ }^{17,18}$ The common carotid artery and the distal internal carotid artery both have a muscular and elastic component. Manninen et $\mathrm{al}^{18}$ consistently found 3 different circumferential signal-intensity patterns in the distal internal carotid artery segment visualized by intravascular sonography, during life and after death. The common carotid artery typically has a characteristic homogeneous structure. ${ }^{18}$ The arterial wall of the internal carotid artery bulb can have marked variation because it is typically a transitional zone. With regard to various parts of the carotid artery wall imaged by intravascular sonography, there appears to be a continuum of findings. ${ }^{18}$ Mural thrombus, freefloating clot, and echolucent disease like neointimal hyperplasia 
Characteristics of sonographic modalities used for imaging cerebrovascular circulation

\begin{tabular}{|c|c|c|c|}
\hline Study & Location & Frequency & Common Usage \\
\hline Transcranial Doppler & Extracranial (extravascular) & Multiples of $2 \mathrm{MHz}$ & Measures velocity of blood through intracranial vessels \\
\hline Carotid duplex ultrasonography & Extracranial (extravascular) & $5-10 \mathrm{MHz}$ & $\begin{array}{l}\text { Duplex procedure: brightness mode (B-mode) allows } \\
\text { imaging and Doppler imaging enables color-flow } \\
\text { volume and directional information; spectral analysis } \\
\text { measures blood flow velocity; measures intimal } \\
\text { medial thickness and evaluates stenosis }\end{array}$ \\
\hline Intravascular ultrasound & Intracranial, extracranial (intravascular) & $20-40 \mathrm{MHz}$ & $\begin{array}{l}\text { Determination of morphology and composition of } \\
\text { atherosclerotic plaque within the extracranial and } \\
\text { intracranial circulation; allows evaluation of correct } \\
\text { stent diameter and the amount of balloon inflation } \\
\text { pressure needed during angioplasty; enables } \\
\text { visualization of stent apposition and expansion, } \\
\text { mural thrombus, plaque ulceration, and aneurysm } \\
\text { and vessel dissection }\end{array}$ \\
\hline
\end{tabular}

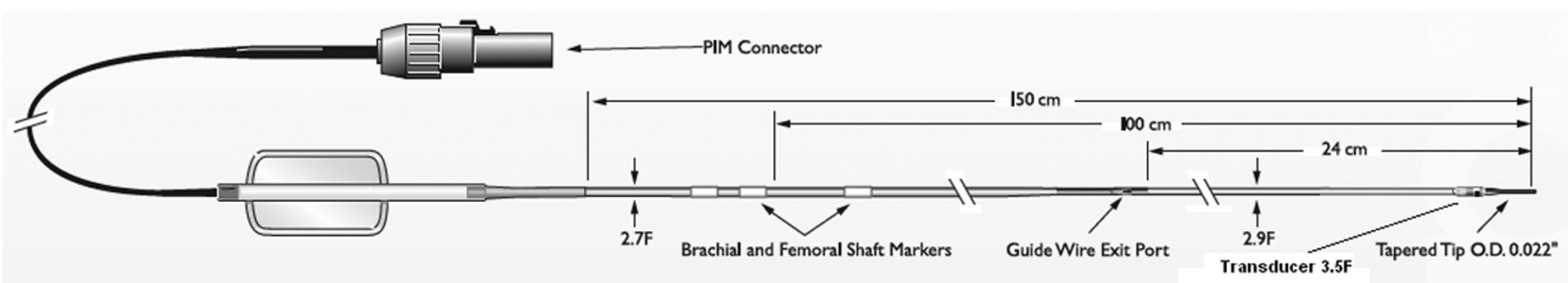

A

Eagle Eye Gold Intravascular Ultrasound Imaging Catheter

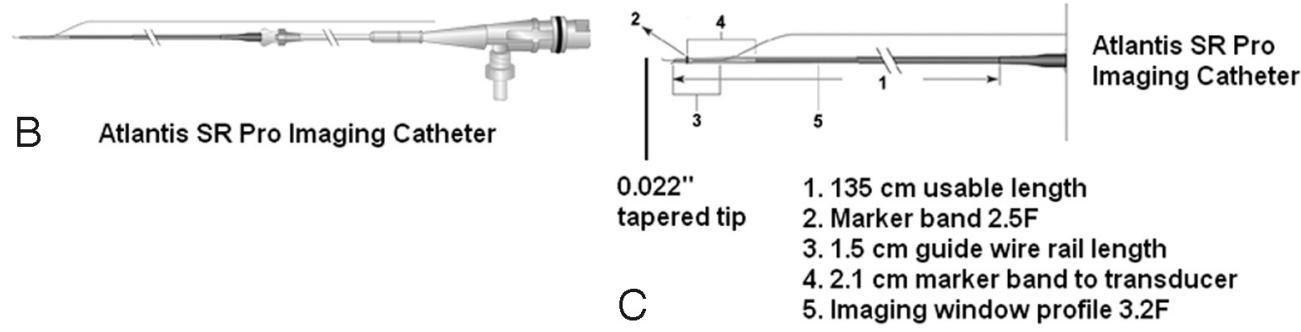

Fig 1. Intravascular sonography catheters, components, and signal-intensity characteristics. A, Eagle Eye Gold imaging catheter (20 MHz, Volcano Corporation). B and $C$, Atlantis SR Pro imaging catheter (40 MHz, Boston Scientific).

all have a dark appearance, similar to luminal blood flow on conventional gray-scale intravascular sonography. ${ }^{19}$

\section{Intravascular Sonography Characteristics of Specific Plaque Components}

Lipid Content. Intravascular sonography studies of the coronary and carotid artery plaques can delineate lipid deposition. These lipid depositions appear as echolucent (hypoechoic) zones within the atherosclerotic plaque. ${ }^{20}$ Potkin et $\mathrm{al}^{21}$ found that in vitro conventional intravascular sonography correctly identified 78\% (7 of 9) of lipid-containing plaques that were confirmed by histologic analysis. The sensitivity of the identification of these lipid depositions was dependent on the amount of lipid present within the atherosclerotic plaque. If the echolucent area was smaller than one-quarter of the plaque, the sensitivity of detection was reduced. ${ }^{22}$ The interpretation of echolucent areas is complex because a similar signal intensity can be generated by loose tissue and acoustic shadowing from calcium deposits. The ability to differentiate fibrous and fatty tissue also varies depending on the intravascular sonography system used. ${ }^{23}$

The stage of plaque progression may be identified by differentiating an unstable atherosclerotic plaque at risk for caus- ing an embolic event from a stable plaque with low thrombogenic potential. Pathologic studies in coronary arteries have demonstrated that plaque rupture is more frequent in eccentric lipid-rich soft plaques with a thin fibrous cap overlying the plaque. $^{24-30}$

A large histopathologic study found an association between stroke and carotid artery plaque rupture and mural thrombosis. ${ }^{31}$ Following the initial rupture, the thrombotically active plaques may remain unstable, and further cerebral events may develop during this "vulnerable plaque" state because of subsequent embolization. ${ }^{31,32}$ Studies characterizing coronary arteries have shown an association between sudden death and rupture of a plaque with a necrotic lipid core (echolucent center). Intravascular sonography may be used to identify highrisk asymptomatic patients with carotid lesions by identifying carotid atherosclerotic plaques containing a high proportion of a necrotic lipid core. ${ }^{33-37}$ Further studies by using virtual histology intravascular sonography are required to understand the full potential in regard to validating the interpretation of plaque progression. ${ }^{37-41}$

Plaque Ulcerations. Intravascular sonography has been used to visualize small carotid plaque ulcerations. The risk of cerebral embolism may be increased in the presence of carotid 


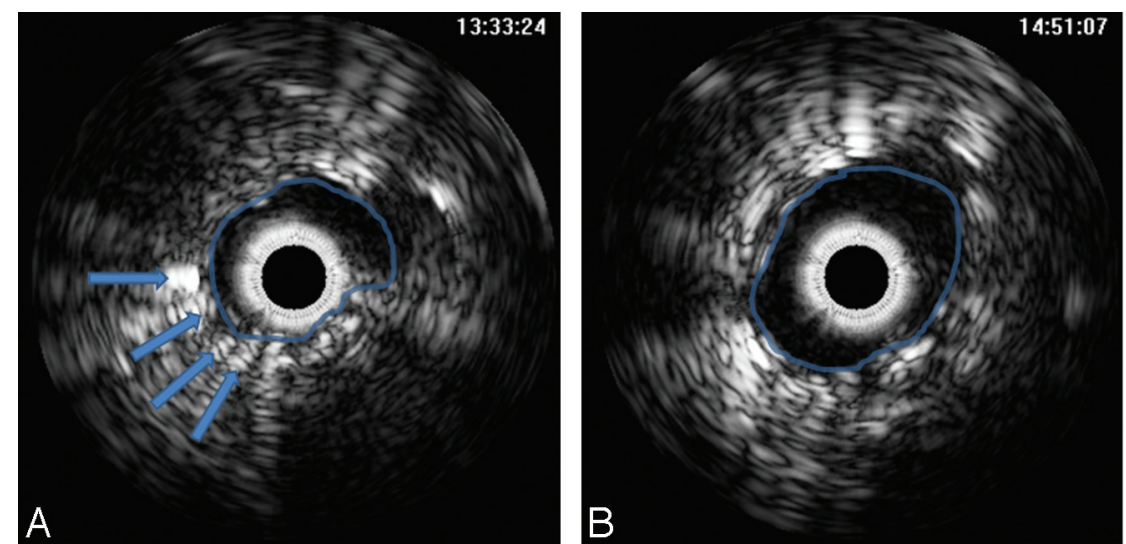

Fig 2. A, Conventional intravascular sonography image demonstrates severe stenosis with plaque outside the struts of the carotid stent (arrows). No plaque inside the stent is identified. $B$, There is improvement in vessel lumen diameter after poststent angioplasty.

plaque ulcerations, which may predispose to thromboembolic events by releasing plaque materials into the arterial lumen. ${ }^{6}$ An apparent hole (small cavity) in the plaque is the classic appearance of an ulceration on intravascular sonography. Fisher and Ojemann ${ }^{42}$ applied the phrase "cul de sac" to explain the shape of the ulceration on gross morphology. The prevalence of carotid ulceration varies among patients. Streifler et $\mathrm{al}^{43}$ and Fürst et $\mathrm{al}^{44}$ found a high prevalence of ulceration in a select group of patients who underwent carotid endarterectomy.

An in vitro study of human carotid arteries conducted by Miskolczi et $\mathrm{al}^{6}$ found that $29 \%$ of the arteries had at least 1 ulceration and that intravascular sonography (90\%-100\% sensitivity) accurately identified all ulcerated arteries. According to Miskolczi et al, ${ }^{6}$ the minimum predefined depth of the ulceration (a minimum of $\geq 0.5 \mathrm{~mm}$ ) was within the resolution limits of the intravascular sonography system (Sonicath $30 \mathrm{MHz}$, 3.5F sonographic probe; Boston Scientific, Natick, Massachusetts). When compared with gross histologic measurements of the ulcerations, the intravascular sonography measurements underestimated the depth of penetration of the carotid plaque ulceration $(1.05 \pm 0.44 \mathrm{~mm}$ versus $1 \pm 0.36$ $\mathrm{mm})$ and orifice diameter $(1.95 \pm 0.72 \mathrm{~mm}$ versus $1.76 \pm 0.59$ $\mathrm{mm}) .{ }^{6}$ The investigators concluded that intravascular sonography was a more sensitive technique for the identification of small ulcerations in comparison with digital subtraction angiography, B-mode sonography, duplex sonography, or colorflow sonography. ${ }^{6}$

Plaque Calcification. Intravascular sonography can effectively identify calcium deposits within the atherosclerotic plaque. ${ }^{13}$ Atherosclerotic plaques that contain calcifications are characterized by a bright echo signal intensity (hyperechoic) with distal shadowing, which may hide other plaque components and deeper vessel structures. ${ }^{22}$ Determination of the actual dimensions of the carotid atherosclerotic plaque and the percentage stenosis may be difficult in situations in which intravascular sonography identifies superficial platelike calcifications. ${ }^{18}$ Kostamaa et $\mathrm{al}^{45}$ found that intravascular sonography underestimated the total calcified plaque crosssectional area by $39 \%$ because the sonography beam could not penetrate through the intralesional calcium deposits. The identification of arterial calcification is very important because calcification can lead to a noncompliant lesion resistant to balloon angioplasty. The presence of heavy intra-arterial calcification, especially in combination with arterial tortuosity, also causes difficulties in tracking devices, lesion dilation, stent positioning, and adequate stent expansion.

Coronary plaque calcification has been detected with a sensitivity between $86 \%$ and $97 \%$, in comparative studies done by using both histology and intravascular sonography. ${ }^{46,47}$ Friedrich et $\mathrm{al}^{48}$ also studied 50 fresh coronary vessel segments with intravascular sonography and compared their results with the corresponding histologic sections. Intravascular sonography correctly identified $89 \%$ (16 of 18 ) of cases with attenuated calcified plaques, $17 \%$ (2 of 12) of cases with microcalcification (small calcium flecks $\leq 0.5 \mathrm{~mm}$ ), and 100\% (3 of 3 ) of the cases with a combination of calcified plaque surrounded by small calcium flecks. ${ }^{48}$ In an intravascular sonography study of the carotid arteries, Manninen et al ${ }^{18}$ similarly found that the macroscopic calcifications were consistently detected, but disseminated microcalcifications were mainly missed.

Mural Thrombus. A mural thrombus may be found attached to the endothelium or to an ulcerated surface of a carotid atherosclerotic plaque and may appear as a thickened echodense region on intravascular sonography. ${ }^{6}$ The echodensity and ultimately the visibility of the thrombus in the carotid artery in vivo depend on its red blood cell content. ${ }^{49}$ The intensity (echogenicity) increases with increasing red blood cell content. ${ }^{49}$ Thrombi that are platelet-rich have a predominantly echolucent (low echogenicity) pattern on intravascular sonography. ${ }^{49}$

\section{Classification of Plaques Based on Composition}

Intravascular sonography characterizes the following components of coronary/carotid atherosclerotic plaques: 1) size of the lipid (echolucent) core, 2) thickness of the fibrous cap, 3 ) presence of inflammatory cells, 4) amount of remodeling and extent of plaque-free vessel wall, and 5) 3D morphology. ${ }^{50}$ Vulnerable (unstable) plaques (ie, intra-arterial plaques that have a high probability of rupture) can be detected by using intravascular sonography in both the extracranial and intracranial arterial circulation. ${ }^{34,51}$ Vulnerable (soft) plaques contain a large lipid core, typically making up $40 \%$ of the entire plaque. ${ }^{22}$ Atherosclerotic plaques containing large amounts of calcification are more stable. The differentiation of "soft" (un- 
stable) from "fibrotic" (stable) plaque is highly dependent on the gain settings used during intravascular sonography. ${ }^{52}$ Structures sized $>160 \mu \mathrm{m}$ can be estimated accurately by intravascular sonography. ${ }^{22}$

With intravascular sonography, the areas of the arterial lumen and of the external elastic membrane of the vessel can be measured, with subsequent calculation of the atherosclerotic plaque area. ${ }^{18,53-56}$ Coronary artery vessels have demonstrated an ability to remodel themselves at the location of the coronary atherosclerotic plaque. Positive remodeling represents the compensatory increase in the local vessel size in response to an increase in plaque burden. Negative remodeling represents the local shrinkage of vessel size in response to an increase in plaque burden. ${ }^{55}$ Intravascular sonography can also be used to evaluate carotid artery vessel wall remodeling secondary to the presence of an atherosclerotic plaque.

\section{Limitations of Conventional Intravascular Sonography}

The frequency of the transducer, gain settings, depth of penetration, and focal depth are some of the factors that affect the sensitivity of the intravascular sonography imaging. The location and orientation of the imaging probe within the arterial lumen also influence the appearance of the vessel wall structure. ${ }^{17}$ Lateral impulse response artifacts can occur when the sonographic catheter is eccentrically placed, resulting in an image that falsely suggests the presence of an intimal flap or ulceration. $^{6,57}$ The dark images obtained through conventional gray-scale intravascular sonography can make it difficult to distinguish the lumen from the dark echolucent plaque. Accurate delineation of the medial adventitial interface, leading to the appropriate sizing and imaging of lesions, has been achieved with intravascular sonography of the carotid arteries between 20 and $40 \mathrm{MHz}$. ${ }^{6,7,18,38,58}$ An in vitro study found the differentiation of the atherosclerotic plaque from the underlying media may be difficult at times with conventional intravascular sonography. ${ }^{17,18}$ Manninen et $\mathrm{al}^{18}$ found that optimal resolution in arteries 3-6 $\mathrm{mm}$ in diameter was obtained by a $30-\mathrm{MHz}$ transducer, giving a maximum radius of penetration of approximately $5 \mathrm{~mm}$. Miskolczi et $\mathrm{al}^{6}$ observed that a $30-$ $\mathrm{MHz}$ sonographic system imaged adequately within a distance of 2-3 mm between the intimal surface of the carotid artery and the transducer if the catheter was placed in a central position. However, at times, lesions at the intimal surface may not be adequately visualized because they fall below the resolution limit of the intravascular sonography system being used or they are being obscured by the contents of the atherosclerotic plaque. Deep calcifications within the carotid atherosclerotic plaque may limit the ability of intravascular sonography to evaluate the diameter of the stenosis properly. ${ }^{17,18}$ If the intravascular sonography device is not in the plane perpendicular to the lesion, artifacts may be seen, which may be over-read by an inexperienced operator. ${ }^{59}$

Vessel injury or dissection and inadvertent atherosclerotic plaque rupture may rarely occur when the intravascular sonography catheter is passed through an area with a highgrade stenosis. ${ }^{59}$ Imaging of the intracranial circulation has been limited due to the difficulty in navigating through the intracranial vessels secondary to the narrow course and marked tortuosity of the vessels. ${ }^{59}$

\section{Color-Flow Intravascular Sonography}

Color-flow intravascular sonography was introduced to provide a greater understanding of intraluminal blood flow, lumen size, success of endovascular treatment, and the interface between the vessel wall and the blood stream. ${ }^{7}$ Real-time images are produced from the transducer of the intravascular sonography apparatus at 30 frames per second. The difference between 2 sequential adjacent frames is detected by computer software producing the color-flow intravascular sonography images. Red demonstrates the movement of echogenic blood particles through the artery. A transition in the color representation from red to orange is seen when there is a vascular stenosis, resulting in an increase in the speed of blood through that segment. ${ }^{7}$ The main benefit of color-flow intravascular sonography lies in its ability to distinguish luminal blood flow from the dark echolucent disease along the vessel wall. ${ }^{19,60,61}$

Color-flow intravascular sonography can also identify soft echolucent plaques, ulcerations, thrombus, and arterial dissections. ${ }^{19}$ In the case of arterial dissections, the probe should be placed in the true lumen, where there is better blood flow visualization. ${ }^{7}$ A reduction in conventional angiography and total radiation dosage was observed after the introduction of color-flow intravascular sonography in percutaneous coronary interventions. ${ }^{19}$ Diethrich et $\mathrm{al}^{7}$ used color-flow intravascular sonography with fluoroscopy alone to treat patients and deploy stents and endoluminal grafts, avoiding the use of conventional angiography in patients with renal failure or contrast allergy. Following intervention, the demonstration of blood flow through color-flow intravascular sonography enabled the treating physician to evaluate the success of the treatment, without the use of angiography. ${ }^{7}$

Accurate stent deployment at the site of the origin of the common carotid artery, from the aortic arch, is another potential clinical application of the color-flow sonography. ${ }^{62}$ Due to the curvature of the aortic arch, relying on angiography alone for the accurate stent placement of occlusive disease is difficult. Fluoroscopy can be used to visualize the radiopaque color-flow intravascular sonography transducer and guide it into position. Once the transducer is moved from the stenotic area into the aorta, the color-flow intravascular sonography can detect a sudden change in the size of the color flow. This sudden change in the color flow enables the precise identification of the origin, ultimately leading to a more accurate stent deployment. $^{62}$

Irshad et $\mathrm{al}^{19}$ used a 3.5F 20-MHz intravascular catheter that used ChromaFlo computer software (EndoSonics, Rancho Cordova, California) to demonstrate blood flow in $>100$ peripheral interventions. Color-flow intravascular sonography assisted in balloon catheter angioplasty when treating stenotic arterial lesions, according to the authors' interpretation. The results obtained through angiographic measurements alone were inconsistent when compared with the measurements obtained by intravascular sonography. Irshad et $\mathrm{al}^{19}$ treated a patient with a critically ischemic foot with what angiographically was assessed to be a minimal superficial femoral artery stenosis. Color-flow intravascular sonography measurement of the stenotic lesion found it to be a $70 \%$ crosssectional area reduction. A Jostent covered stent (Abbott Vascular, Redwood City, California) was placed after it was determined that balloon angioplasty had not improved the 


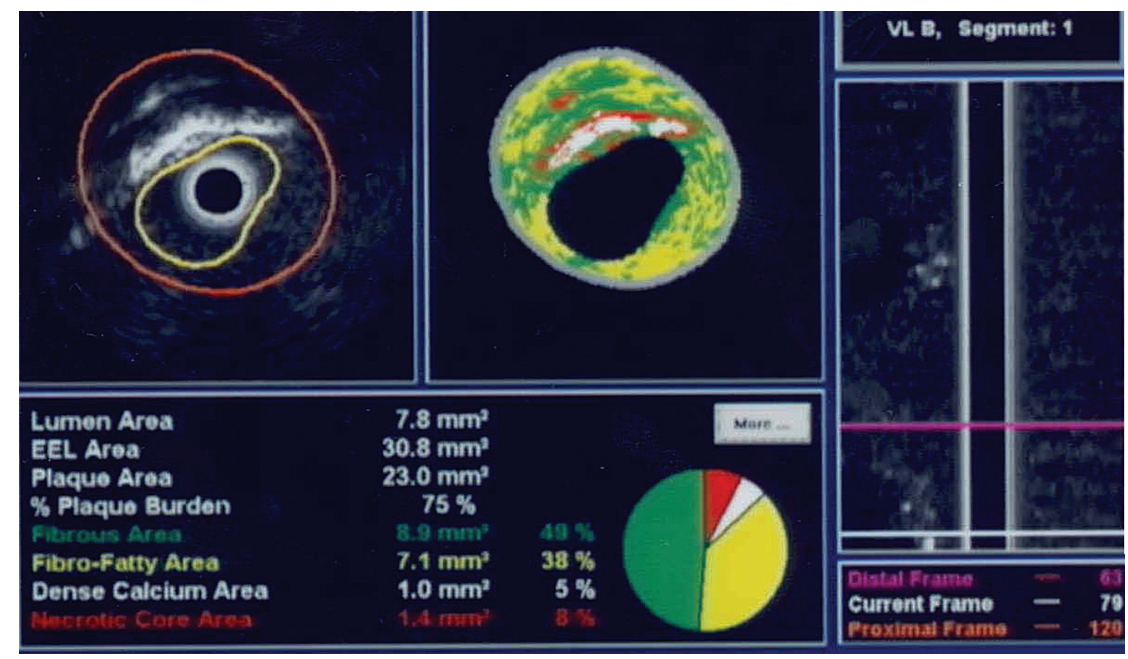

Fig 3. Virtual histology intravascular sonography mapping of carotid atherosclerotic plaque. The image demonstrates various components as follows: dark green, fibrous material; yellow/green, fibrofatty component; white, calcification; and red, necrotic lipid core.

stenosis when assessed by intravascular sonography. It is anticipated that color-flow intravascular sonography may be used in a similar manner to evaluate the intracranial and extracranial environment.

The short scanning diameter is a limitation of color-flow intravascular sonography. ChromaFlo imaging was found to have a 14 -mm scanning diameter. ${ }^{19}$ The entire vessel lumen may not generate a colored signal intensity, especially if the probe is against the vessel wall in a large artery. Blood flow may not be detected in the case in which large-caliber sheaths are used, due to the possibility that the catheter itself may impede the flow of blood through the vessel. ${ }^{7}$ Despite high image resolution with this technique, flow velocities cannot be calculated. Color flow cannot be performed when virtual histology intravascular sonography images are obtained because the software that is used to acquire and interpret the data is different for each technique. Furthermore, color-flow intravascular sonograms are not gated with the heart rate. ${ }^{7}$

\section{Virtual Histology Map by Intravascular Sonography}

The components of the vessel wall reflect the sonography signal intensity at different frequencies and intensities, creating an opportunity for histologic details to be detected through the generation of a virtual histology intravascular sonography map. With autoregressive analysis of radio-frequency signals, real-time dynamic assessment of plaque morphology can be performed. ${ }^{63}$ This technique enables the creation of a virtual histology map of the atherosclerotic plaque, distinguishing between its various contents. The plaque may contain a varying amount of fibrous material, fibrofatty content, calcium deposits, and a lipid core. ${ }^{7}$ A histologic classification and a colorcoded map of the plaque can be produced as a result of the comparison of virtual histology maps with the true histologic sections of diseased coronary arteries. A color-coded map currently provides detailed information about the contents of the plaque: dark green represents fibrous material, yellow/green represents fibrofatty content, white represents calcified deposits, and red represents the necrotic lipid core (Fig 3). ${ }^{64-66}$ Accurate information regarding the composition of the carotid atherosclerotic plaque can guide the neurointerventionalist to determine the resistance to balloon dilation or the potential for embolic phenomenon. ${ }^{7,24}$

The Carotid Artery Plaque Virtual Histology Evaluation study was performed by Diethrich et $\mathrm{al}^{67}$ to determine the diagnostic accuracy of the virtual histology intravascular sonography imaging of carotid plaque and to assess the feasibility of this technique in identifying carotid atherosclerotic plaque with embolic potential in patients undergoing carotid artery stent placement. Thirty patients were nonrandomly selected to participate in a single-center prospective 2-arm feasibility study. In the first arm, 15 patients underwent virtual histology intravascular sonography evaluation of the carotid plaque with a cerebral protection device, immediately followed by carotid endarterectomy. ${ }^{67}$ In the second arm, 15 patients underwent a preliminary virtual histology intravascular sonography mapping of the carotid atherosclerotic lesion with a cerebral protection device in place, before carotid artery stent placement. The findings of virtual histology intravascular sonography were in agreement with those of true histology (acquired from surgical specimens) in different carotid plaque types, demonstrating a strong diagnostic accuracy for each component as follows: $99.4 \%$ in thin-cap fibroatheroma, $96.1 \%$ for calcified thin-cap fibroatheroma, $85.9 \%$ in fibroatheroma, $85.5 \%$ for fibrocalcific atheroma, $83.4 \%$ in pathologic intimal thickening, and $72.4 \%$ for calcified fibroatheroma. ${ }^{67}$

Interpretation of the results of virtual histology maps requires experience. An increase in computing speed and improved software for interpretation are also needed. The modalities of color flow and virtual histology cannot be used simultaneously. The process is time-consuming, because adjustments to the borders that delineate the plaque are usually necessary, sometimes requiring multiple placements of the intravascular sonography transducer across the lesion. Metal stent struts can be misread as calcification, colored white on virtual histology intravascular sonography, limiting its value after percutaneous carotid stent placement. ${ }^{7}$ Okubo et $\mathrm{al}^{63}$ found that the virtual histology function of the intravascular sonography overestimated the presence of the necrotic core in the atherosclerotic plaque when located particularly close to 
the vessel lumen, potentially leading to an overestimation of a thin-cap fibroatheroma.

\section{Integrated Backscatter Intravascular Sonography}

Integrated backscatter intravascular sonography reflects the tissue characteristics of human coronary atherosclerotic plaque composition by using a different algorithm than the virtual histology intravascular sonography mapping. Similar to virtual histology intravascular sonography, the integrated backscatter intravascular sonography also produces a colorcoded map of the atherosclerotic plaque. The color-coded map generated by integrated backscatter represents slightly different components in the atherosclerotic plaque: fibrous (green), dense fibrosis (yellow), lipid pool (blue), and calcification (red). ${ }^{63}$

Tissue characterization is distorted when the lesions are not perpendicular to the axis of the intravascular sonography probe. ${ }^{63}$ Angular scattering behavior depends on the type of plaque insonated. Plaques largely composed of calcified or fibrous tissue have a larger angular scattering behavior versus the normal and fatty plaque. ${ }^{68,69}$ Similar to the limitations of conventional intravascular sonography, the angle of dependence necessary to accurately visualize the atherosclerotic plaques depends on the strength of the signal intensity produced by the intravascular sonographic equipment being used. $^{63}$

Integrated backscatter intravascular sonography, similar to conventional intravascular sonography, is limited in its ability to visualize atherosclerotic plaques that contain a calcified layer due to the obscuration by calcification. Acoustic shadowing of the sonographic signal intensity is also seen when the tissue being evaluated is covered by stents, making the integrated backscatter intravascular sonography ineffective. ${ }^{63}$ Atherosclerotic plaques that have an attenuated fibrous composition may also lead to acoustic shadowing mimicking the signal intensity produced by calcification. ${ }^{63}$ Okubo et a ${ }^{63}$ discussed the possibility that the presence of the guidewire, used during in vivo studies, may decrease the diagnostic accuracy of such intravascular sonography. The detection of intra-arterial thrombus requires the analysis of integrated backscatter intravascular sonographic values in multiple cross-sections with time.

Okubo et $\mathrm{al}^{63}$ found that integrated backscatter intravascular sonography led to a false-positive diagnosis of lipid-rich lesions, when in actuality, the histologic analysis showed that the atherosclerotic plaques were made up of smaller lipid accumulations within a predominantly fibrous lesion. In this particular study, integrated backscatter intravascular sonography overestimated lipid-rich lesions and underestimated fibrous lesions. ${ }^{63}$

\section{Comparison of Integrated Backscatter and Virtual Histology Sonography Mapping Techniques}

Both the integrated backscatter and virtual histology intravascular sonography modalities evaluate the composition of atherosclerotic plaques. Okubo et $\mathrm{al}^{63}$ compared integrated backscatter sonographic images acquired by a $40-\mathrm{MHz}$ mechanically rotating intravascular sonography catheter (Atlantis, Boston Scientific) with the virtual histology intravascular sonography images acquired by a $20-\mathrm{MHz}$ phased array cath- eter (Virtual Histology Version 1.4; Volcano, San Diego, California) in coronary arteries of cadaveric specimens. The investigators found that integrated backscatter intravascular sonography was more accurate compared with virtual histology intravascular sonography for tissue characterization of atherosclerotic plaques assessed by actual histology. In the qualitative comparison, the overall agreement between histologic and integrated backscatter-intravascular sonography diagnoses was higher $(\kappa=0.81 ; 95 \%$ CI, $0.74-0.89)$ than that of the virtual histology intravascular sonography diagnoses $(\kappa=$ $0.66 ; 95 \% \mathrm{CI}, 0.56-0.75)$. The percentage fibrosis area determined by integrated backscatter intravascular sonography correlated highly with the relative area of fibrosis identified on histology $(r=0.67, P<.001) .{ }^{63}$ In the quantitative comparison, the overall agreement between the histologic and integrated backscatter intravascular sonography diagnoses was higher $(\kappa=0.83$; $95 \% \mathrm{CI}, 0.75-0.91)$ than that of the virtual histology intravascular sonography diagnoses $(\kappa=0.73$; $95 \%$ CI, 0.63-0.83). ${ }^{63}$

\section{Microbubbles}

Site-targeted acoustic contrast agents have been used to help further identify specific vascular pathology as an adjunct to intravascular sonography. Contrast agents injected during an in vitro intravascular sonography accurately enhanced the intraluminal contours. ${ }^{70}$ Lanza et $\mathrm{al}^{71}$ successfully demonstrated the ability to visualize a vascular thrombus after exposure to a site-specific contrast agent in an in-vitro study. Most studies using this technique have focused on the coronary artery circulation, with very limited study of the carotid circulation.

Studies suggest that proliferation of the vasa vasorum (blood vessels in the adventitial layer), dynamic structural changes in the adventitia, and intraplaque hemorrhage in coronary atherosclerotic plaques precede or occur concomitantly with plaque inflammation and instability. ${ }^{72-74}$ Increased neovascularization of the vasa vasorum and atherosclerotic plaques can be traced with contrast-enhanced intravascular sonography. Lipid microbubbles have been used extensively to identify inflammation within the plaques because these lipid microbubbles are phagocytosed by macrophages within the inflamed plaque. ${ }^{75}$ Subsequently, these phagocytosed microbubbles generate characteristic echogenic features that can be used to identify their distribution within the plaque with realtime intravascular ultrasonography. ${ }^{76-78}$ Vavuranakis et $\mathrm{al}^{76}$ used contrast enhancement with microbubbles in both animal and human models to detect blood flow into the coronary lumen and perivascular flow, as part of contrast-enhanced sonographic images. ${ }^{79}$ In a porcine model, 11 regions of interest within the left anterior descending coronary arteries and left circumflex arteries, including perivascular structures, were compared with corresponding gray-scale intravascular sonography levels before and after the injection of SonoVue contrast (0.06 mL/kg; Bracco Diagnostics, Princeton, New Jersey). A significant $(P=.018)$ enhancement was found in the echogenicity of the total perivascular space (adventitial region and perivascular vessels), as indicated by an increase in gray-level intensity from $8.33 \pm 0.80$ (before) to $10.11 \pm 0.88$ (after microbubble injection). ${ }^{76}$ A significant enhancement of the 11 selected regions of interest (perivascular structures) was also 
recorded after the injection of microbubbles (from $7.92 \pm$ 2.14 to $14.03 \pm 2.44 ; P=.008) .^{76}$

In the human study, Vavuranakis et $\mathrm{al}^{79}$ examined the attenuation of the vasa vasorum in asymptomatic coronary atherosclerotic plaques of 16 patients with acute coronary syndrome, comparing gray-scale intravascular sonography signals before, during, and after intracoronary injection of microbubbles. Qualitative and quantitative analysis of the preand postinjection images showed a significant enhancement in the gray-scale intensity of intima-media and adventitia after injection (intima-media, from $6.0 \pm 2.5 \%$ to $7.9 \pm 3.3 \%, P=$ .006 ; adventitia, from $7.1 \pm 2.2 \%$ to $7.6 \pm 2.5 \% ; P=.035) .{ }^{79}$ These studies demonstrate another potential diagnostic use of contrast-enhanced intravascular sonography in characterizing atherosclerotic plaques.

The carotid arteries are also perfused by the vasa vasorum; therefore, the atherosclerotic plaques are subject to the same phenomenon as that found in the coronary circulation. ${ }^{80-82}$

\section{Comparison of Intravascular Sonography and Angiography}

Intravascular sonography has an advantage over angiography because it provides images from within the vessel, has greater resolution without having to penetrate the extravascular soft tissues, and provides 3D assessments. ${ }^{83}$ Intravascular sonography may have higher sensitivity for detecting intimal thickening, concentric plaques, plaque surface ulceration, and the presence of calcifications than digital subtraction angiography. ${ }^{84}$ Manninen et al $^{18}$ found that contrast-enhanced angiography of a variety of carotid arteries did not detect 10 calcifications that were all visualized with intravascular sonography. Digital subtraction angiography visualized 5 of 17 (29\%) intimal thickenings that were all successfully imaged with intravascular sonography. ${ }^{18}$ Manninen et l $^{18}$ found that digital subtraction angiography of the carotid arteries also missed 2 concentric stenoses $>20 \%$ that were detected by intravascular sonography. Similarly, angiographic contrast agents injected within the coronary arteries can provide very little information regarding perivascular blood flow within the vasa vasorum. ${ }^{76}$ However, intravascular sonography can detect blood flow in perivascular vessels as a result of contrast-generated signal intensity from flowing microbubbles after proper image analysis. $^{76}$

Case reports and observational studies support the advantages of visualizing the common carotid artery using intravascular sonography over common carotid angiography, when evaluating the degree of stenosis within the arterial lumen. A $50 \%$ stenosis of the left common carotid artery was revealed with an angiogram, whereas an $87 \%$ lumen area stenosis with complex superficial calcification was measured from images acquired by using the intravascular sonography in the same patient. ${ }^{83}$ The results of digital subtraction angiography can be obscured by heavy calcification of the vessel border. ${ }^{83}$ Intravascular sonography has also demonstrated the protrusion of superficial calcification within the lumen of the common carotid artery. ${ }^{83}$ Similarly, intravascular sonography revealed some degree of stenosis in $80 \%$ of angiographically normal left main coronary arteries after percutaneous transluminal coronary angioplasty. ${ }^{85}$

A more accurate assessment of carotid artery stent dimensions, expansion, and apposition can be obtained through in- travascular sonography, compared with quantitative carotid angiography. Clark et $\mathrm{al}^{13}$ found that the measurements provided by intravascular sonography of the internal carotid artery stent minimal lumen diameter were significantly smaller than those provided by quantitative carotid angiography ( $3.65 \pm 0.68$ versus $4.31 \pm 0.76 \mathrm{~mm} ; P<.001)$. Intravascular sonographic measurements of the minimal lumen diameter of the distal internal carotid artery reference segment (nonstented) were similar to those of quantitative carotid angiography $(4.60 \pm 0.74 \mathrm{~mm}$ versus $4.74 \pm 0.71 \mathrm{~mm} ; P=.21) .{ }^{13} \mathrm{In}$ $11 \%$ of cases, intravascular sonography also found stent malapposition. ${ }^{13}$ After an optimal result was judged based on angiograms, intravascular sonographic findings led to additional treatment in $9 \%$ of patients (10 patients). Four patients required stent expansion, 3 patients required additional stents to achieve better plaque coverage, and 3 patients were found to have stent malapposition. ${ }^{13}$

Intravascular sonography was more sensitive than angiography in the detection of calcium within the arteries $(61 \%$ versus $46 \%$; $P<.05) .{ }^{13}$ When 3 or 4 quadrants of the carotid arteries were found to have superficial lesion calcification by intravascular sonography, there was a $31 \%$ incidence of ischemic stroke; however, there was a $1 \%$ incidence of ischemic stroke in patients without severe superficial calcification within the vessel. ${ }^{13}$ Reduced stent expansion and less stent symmetry were seen in patients who had severe superficial calcium identified by intravascular sonography. ${ }^{13}$

\section{Safety of Intravascular Sonography}

Intravascular sonography has been a relatively safe procedure in the extracranial and intracranial circulation. However, it is difficult to maneuver the catheter through heavily stenotic lesions and through the tortuous intracranial circulation. The sonography catheter itself may disrupt an atherosclerotic plaque, releasing plaque material, which may lead to embolic stroke. Some investigators recommend heparinization while performing the intravascular sonography to avoid the development of thrombosis. Räsänen et $\mathrm{al}^{16}$ successfully performed intravascular sonographic evaluations of the extracranial carotid arteries of 27 patients (age range, 17-75 years) without any complications. Manninen et $\mathrm{al}^{18}$ did not encounter any adverse effects in 22 patients who underwent in vivo intravascular sonography imaging of their carotid arteries. Similarly, Weissman et $\mathrm{al}^{86}$ did not encounter an adverse event in 102 patients during distal internal carotid artery and common carotid artery imaging by intravascular sonography. An observational study conducted by Clark et $\mathrm{al}^{13}$ found a procedural success of $97 \%$ when using intravascular sonography during percutaneous carotid artery stent placement. At 30 days postprocedure, the stroke rate and combined stroke or death rate was $5 \%$ and $6 \%$, respectively. ${ }^{13}$ One patient had a common carotid artery perforation but ultimately had a successful procedural outcome. ${ }^{13}$ One case report demonstrated the feasibility and safety of intravascular sonography-guided stent angioplasty of an iatrogenic extracranial vertebral artery dissection. ${ }^{87}$ Takayama et al ${ }^{88}$ also did not encounter any complications during the virtual histology intravascular sonography evaluation of a symptomatic intracranial right vertebral artery stenosis. Similarly, Wehman et $\mathrm{al}^{9}$ demonstrated that 
the intravascular sonography mapping of a basilar artery stenosis can be safely performed.

\section{Intravascular Sonography to Study the Effects of Therapeutic Interventions}

Intravascular sonography has been used to monitor atherosclerotic plaque characteristics and atheroma volume in patients who have been actively treated with a variety of lipidlowering pharmacological agents such as an 3-hydroxy-3methylglutaryl-coenzyme A reductase inhibitor (statin), recombinant apolipoprotein A1 Milano-phospholipid complexes, and torcetrapib. ${ }^{1,2,58,89-101}$ The effects of intensive modification of a number of established risk factors like lipid levels and blood pressure on plaque burden can be quantified by using serial intravascular sonographic evaluations. ${ }^{102,103}$

Clementi et $\mathrm{al}^{104}$ used virtual histology intravascular sonography at baseline and after 6 months of treatment to evaluate 29 plaques in 25 patients with diabetes mellitus and angiographic evidence of nonsignificant coronary lesions. $\mathrm{Pa}-$ tients were treated with $80 \mathrm{mg}$ of atorvastatin and $30 \mathrm{mg}$ of pioglitazone daily for 6 months. The mean elastic external membrane volume (343.9 versus $320.5 \mathrm{~mm} ; P<.05$ ) and mean total atheroma volume (179.3 versus $166.6 \mathrm{~mm} ; P<.05)$ were significantly reduced between baseline and follow-up, leading to a $6.3 \%$ mean reduction in total atheroma volume. ${ }^{104}$ Areas of fibrous tissue, fibrolipidic tissue, and calcium decreased during the 6 months of follow-up. The necrotic core of the coronary atheroma increased from $9 \%$ to $14 \%(P<.05) .{ }^{104}$

Recently reported studies (A Study to Evaluate the Effect of Rosuvastatin on Intravascular Ultrasound-Derived Coronary Atheroma Burden [ASTEROID], ${ }^{105}$ Measuring Effects on Intima Media Thickness: an Evaluation of Rosuvastatin [METEOR], ${ }^{106}$ Reversal of Atherosclerosis with Aggressive Lipid Lowering Therapy [REVERSAL], ${ }^{107}$ and Strategy To Reduce Atherosclerosis Development Involving Administration of Rimonabant - the Intravascular Ultrasound Study [STRADIVARIUS $]^{108}$ ) have demonstrated that pharmacologic interventions can lead to plaque regression in various arterial beds. ${ }^{109}$ The double-blind randomized clinical trial, Assessment on the Prevention of Progression by Rosiglitazone on Atherosclerosis in Diabetes Patients with Cardiovascular History trial, will be using serial intravascular sonography studies to evaluate the progression of coronary atherosclerosis in high-risk patients with coronary artery disease and type 2 diabetes mellitus, randomized to either rosiglitazone or glipizide treatment for 18 months. The primary end point of this clinical trial is the change in percentage atheroma volume, as measured by intravascular sonography, from baseline to study completion in a nonintervened coronary artery. ${ }^{110}$ Virtual histology intravascular sonography will also be used in the multicenter randomized placebo-controlled trial, Pioglitazone for Prevention of restenosis in diabetes, with complex lesion (PIPER) trial. ${ }^{104}$

\section{Intravascular Sonography and Percutaneous Carotid Artery Stent Placement}

Intravascular sonography assists in extracranial and intracranial stent placement by helping select the correct stent diameter and the amount of balloon inflation pressure required

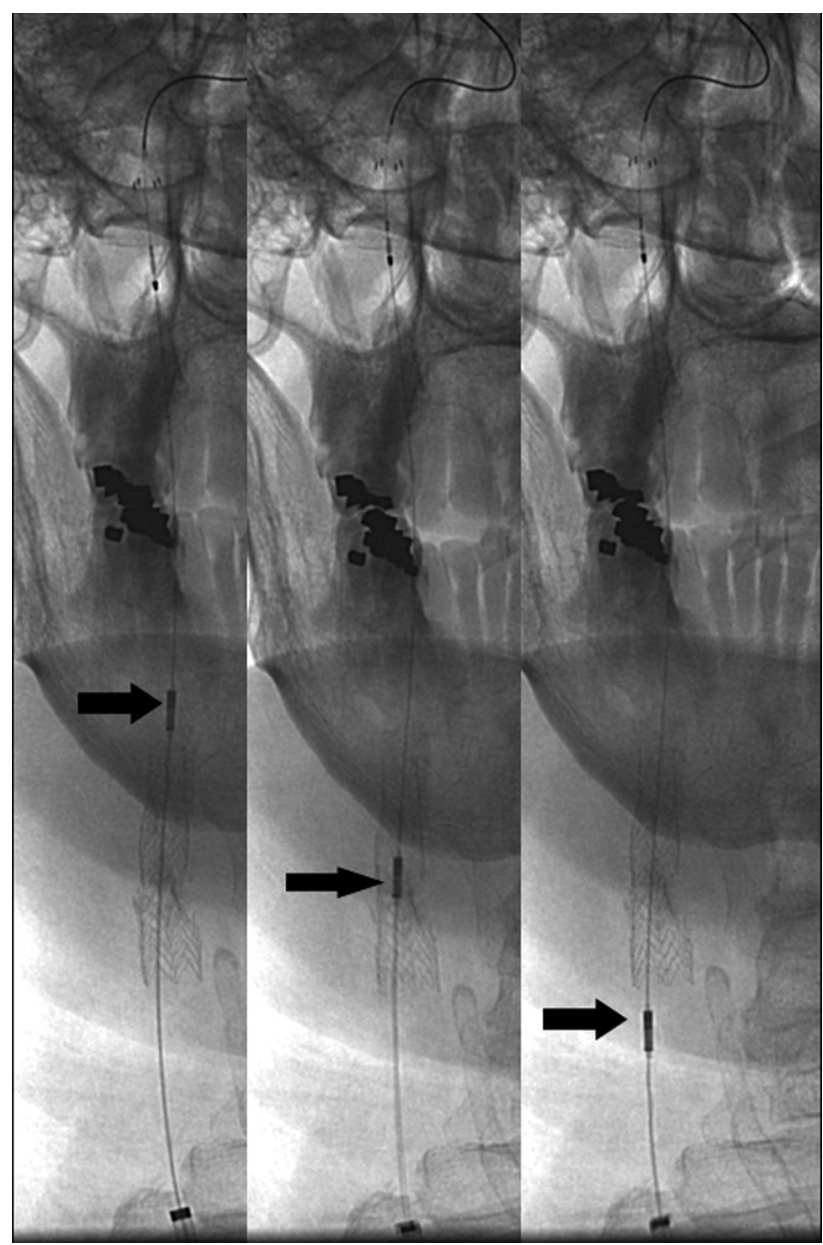

Fig 4. Angiographic images demonstrate a retraction of the intravascular sonographic probe (arrows) by using a motorized device (not shown) after carotid stent placement to visualize any residual stenosis and apposition of the stent to the surrounding vessel wall.

during angioplasty. ${ }^{9,11,12,14,111-113}$ In preparing for balloon inflation, identification of arterial calcification is important because the calcification can produce a noncompliant lesion that necessitates the use of high balloon-inflation pressures. ${ }^{114} \mathrm{In}$ addition, the images provide an accurate method for understanding whether the stent deployment has expanded the lumen to the desired size or if there is a need for further poststent balloon angioplasty. ${ }^{9,12,38,115}$

The length of the stent necessary to cover coronary lesions completely has been determined through the measurements made by intravascular sonography. ${ }^{116,117}$ Intravascular sonography has been used in a similar fashion in extracranial and intracranial arterial stenoses. ${ }^{9}$

Intravascular sonography measures the minimum lumen diameter and minimum lumen area during pre- and postpercutaneous carotid artery balloon angioplasty and stent placement (Fig 4). ${ }^{62-118}$ The gray-scale intravascular sonography accurately determines the poststent lumen diameter. ${ }^{118}$ Irshad et $\mathrm{al}^{38}$ recommended using gray-scale or color-flow intravascular sonography instead of virtual histology maps when confirming proper stent deployment.

\section{Intracranial Application of Intravascular Sonography}

Intravascular sonography may be used to identify carotid artery atherosclerotic plaques in high-risk asymptomatic pa- 
tients so that treatment can be rendered before the development of stroke, transient ischemic attack, or retinal ischemic events. Similarly, intracranial stenoses may be better visualized and characterized on the basis of their composition, plaque area and percentage stenosis, which may guide the treatment chosen. Meyers et $\mathrm{al}^{119}$ reported the results of intravascular sonographic imaging of the intracranial circulation in a 35-year-old man with recurrent ischemic strokes. Intravascular sonography identified an $85 \%$ occlusion of the petrous portion of the right internal carotid artery due to an atherosclerotic plaque with intraplaque hemorrhage. ${ }^{119}$ The findings of intravascular sonographic imaging led to an intracranial stent-supported angioplasty.

Virtual histology intravascular sonography (Eagle Eye Gold, 2.9F, 20-MHz catheter; Volcano) has been used to image a percutaneous transluminal angioplasty and stent-treated symptomatic intracranial right vertebral artery stenosis to characterize the plaque and guide treatment, according to Takayama et al. ${ }^{87}$ The lesion was predilated by using a balloon catheter. With the conventional intravascular data, the vessel media diameter was found to be $5.9 \times 6 \mathrm{~mm} .{ }^{87}$ The plaque components were identified through the virtual histology analysis: fibrous (72\%), fibrofatty (17\%), necrotic core $(7 \%)$, and attenuated calcium (4\%) components. ${ }^{87}$ Virtual histology intravascular sonography demonstrated the ability to identify a stable plaque and provide a better estimate of the size of the balloon-expandable stent needed for treatment. Takayama et $\mathrm{al}^{87}$ acknowledged that virtual histology intravascular sonography differentiated the atherosclerotic plaque causing the stenosis as being unstable or stable or containing high calcification. Wehman et $\mathrm{al}^{9}$ also successfully applied intravascular sonography to evaluate a re-stenotic atherosclerotic lesion of the basilar artery before stent placement, without complication.

\section{Intravascular Sonography and Restenosis}

Vascular remodeling after angioplasty and stent placement can be evaluated with intravascular sonography. ${ }^{120}$ Factors predisposing to restenosis such as postangioplasty lumen diameter, area, and plaque percentage can be quantified by intravascular sonography. ${ }^{121}$ A higher risk of restenosis has been found when a small postprocedural carotid stent diameter and reduced stent expansion were identified by intravascular sonography. ${ }^{13,122-124}$ Stent underexpansion and deformity were not reliably detected before imaging by intravascular sonography. ${ }^{125,126}$ Findings of intravascular sonography imaging have suggested that balloon-expandable endovascular stents within carotid arteries may be subject to 2 types of compressive forces that lead to stent deformation and restenosis: 1 ) 2-point compressive force causing eccentric deformation, and 2) multidirectional compressive force causing complete circumferential encroachment of the stent struts around the catheter. ${ }^{125,127,128}$ Rosenfield et al ${ }^{125}$ found that intravascular sonography (20 MHz, 3.5F; Sonicath, Boston Scientific) was more sensitive than angiography when detecting restenosis of endovascular stents secondary to stent compression. In another study, 3F Atlantis SR Pro 40-MHz intravascular sonography (Boston Scientific) was used to evaluate the degree of stenosis and the mechanism leading to the restenosis of a stent within the extracranial left vertebral artery, which was placed 5 months before imaging. An approximate 66\% stenosis was seen distal to the stent on CT angiography, and an approximate $40 \%$ stenosis was found with a cerebral angiogram. Intravascular sonography demonstrated an approximate $70 \%$ degree of stenosis and new plaque formation at the distal margins of the stent as the culprit for the restenosis, instead of intimal hyperplasia, ultimately guiding the treatment decision. $^{59}$

\section{Intravascular Sonography: Aneurysm and Dissection}

Intravascular sonography can complement MR imaging and 3D-CT angiography in the treatment and diagnosis of cervical arterial aneurysms. Intravascular sonography mapping was used to identify a carotid artery aneurysm proximal to a stent graft, initially placed to treat radiation-induced carotid arteriopathy. ${ }^{129}$ Intravascular sonography also accurately measured the most distal and proximal extents of an intracranial dissection of the left internal carotid artery and identified whether the entire length of the dissection was covered by the stents after treatment. ${ }^{9,130,131}$ The confirmation that the entire dissected lesion has been covered by stents is important because recanalization can occur from a distal damaged section in the event that only the proximal entry point of the dissection is treated. ${ }^{9}$ Color-flow intravascular sonography imaging can demonstrate trace flow of blood into the true lumen of an arterial dissection.

Aneurysm wall composition, intra-aneurysmal contents (eg, thrombus or calcification), and the aneurysm neck can be better defined by using intravascular sonographic imaging. ${ }^{1,132,133}$ The diagnosis of a dissecting aneurysm or pseudoaneurysm is supported by intravascular sonography when a defect of both the hypoechoic (dark) signal intensity of the normal media and the hyperechoic (white) signal intensity of the adventitia are found.

Intravascular ultrasonography has been used in the treatment of an iatrogenic extracranial vertebral artery dissection following a coil embolization of an unruptured right posterior inferior cerebellar artery aneurysm to assist in the placement of a stent and to confirm the true vessel lumen and evaluate the appropriate stent apposition. ${ }^{87}$ Another case report described intravascular sonography-guided stent angioplasty of an iatrogenic extracranial vertebral artery dissection. ${ }^{87}$

\section{Intravascular Sonography: Venous Circulation}

Intravascular sonography has also been used to evaluate the venous circulation. Shindo et $\mathrm{al}^{134}$ used intravascular sonography to map the multiple channels formed by a dural arteriovenous malformation; with the information obtained, transvenous embolization could be performed at the exact fistulous site. Gasparis et al $^{135}$ also used intravascular sonography to demonstrate significant compression of the inferior vena cava below the renal veins and to guide stent placement.

\section{Future Utility of Intravascular Sonography}

With the use of the various intravascular sonographic modalities, a reduction in the rate of ischemic strokes during and after the percutaneous carotid artery stent placement may occur because of identification of intraluminal thrombus and/or carotid plaque histology patterns vulnerable to embolic events. ${ }^{18,136}$ Ruptured plaque or thrombus identified with in- 
travascular sonography after stent evaluation may modify the decision to use intravenous heparin or glycoprotein IIB/IIIA inhibitors before the removal of the distal embolic protection device, ultimately reducing poststent embolic events. ${ }^{13,118,137-143}$ Intravascular sonography can also be potentially used during the treatment of an acute ischemic stroke to help identify the exact composition of the obstructing lesion-calcified versus fibrous versus soft clot. A more aggressive mechanical disruption/ retrieval strategy may be advocated in the presence of calcific or fibrotic occlusion.

\section{Conclusions}

Intravascular sonography provides another potential diagnostic tool to complement the other diagnostic modalities within the already existing neurointerventional practice. Additional benefits may include the following: 1) identification of highrisk patients who should be treated, 2) decrease in postprocedural complication rates, and 3) more accurate identification of postprocedural vascular improvement.

Intravascular sonography is currently an underused diagnostic tool during treatment of extracranial and intracranial arterial diseases. Through technical advancement in different intravascular sonographic modalities and availability of smaller catheter sizes, the intra-arterial and intravenous vasculatures can now be better visualized, leading to more accurate information, which can be obtained before and after a medical or endovascular intervention. Continued application and generation of new data pertaining to these modalities in both the intracranial and extracranial circulation is needed to provide a more evidence-based incorporation into clinical practice.

\section{References}

1. Nissen SE, Tuzcu EM, Schoenhagen P, et al. Effect of intensive compared with moderate lipid-lowering therapy on progression of coronary atherosclerosis: a randomized controlled trial. JAMA 2004;291:1071-80

2. Guedes A, Tardif JC. Intravascular ultrasound assessment of atherosclerosis. Curr Atheroscler Rep 2004;6:219-24

3. Waller BF, Pinkerton CA, Slack JD. Intravascular ultrasound: a histological study of vessels during life-the new "gold standard" for vascular imaging. Circulation 1992;85:2305-10

4. Lockwood GR, Ryan LK, Gotlieb AI, et al. In vitro high resolution intravascular imaging in muscular and elastic arteries. J Am Coll Cardiol 1992;20:153-60

5. Gatzoulis L, Watson RJ, Jordan LB, et al. Three-dimensional forward-viewing intravascular ultrasound imaging of human arteries in vitro. Ultrasound Med Biol 2001:27:969-82

6. Miskolczi L, Guterman LR, Flaherty JD, et al. Depiction of carotid plaque ulceration and other plaque-related disorders by intravascular sonography: a flow chamber study. AJNR Am J Neuroradiol 1996;17:1881-90

7. Diethrich EB, Irshad K, Reid DB. Virtual histology and color flow intravascular ultrasound in peripheral interventions. Semin Vasc Surg 2006;19:155-62

8. Tozzi P, Mallabiabarrena I, von Segesser LK, et al. Intravascular ultrasound underestimates vessel dimensions. Eur J Vasc Endovasc Surg 2000;19:501-03

9. Wehman, JC, Holmes DR Jr, Hanel RA, et al. Intravascular ultrasound for intracranial angioplasty and stent placement: technical case report. Neurosurgery 2006;59(4 suppl 2):ONSE481-83, discussion ONSE483.

10. Uren NG, Schwarzacher SP, Metz JA, et al. Predictors and outcomes of stent thrombosis: an intravascular ultrasound registry. Eur Heart J 2002;23:124-32

11. Satler LF, Hoffmann R, Lansky A, et al. Carotid stent-assisted angioplasty: preliminary technique, angiography, and intravascular ultrasound observations. J Invasive Cardiol 1996;8:23-30

12. Reid DB, Diethrich EB, Marx P, et al. Intravascular ultrasound assessment in carotid interventions. J Endovasc Surg 1996;3:203-10

13. Clark DJ, Lessio S, O'Donoghue M, et al. Safety and utility of intravascular ultrasound-guided carotid artery stenting. Catheter Cardiovasc Interv 2004;6:355-62
14. Blessing E, Hausmann D, Sturm M, et al. Intravascular ultrasound and stent implantation: intraobserver and interobserver variability. Am Heart J 1999; $137: 368-71$

15. Tobis JM, Mallery JA, Mahon D, et al. Intravascular ultrasound imaging: a new method for guiding interventional vascular procedures. Echocardiography 1990;7:415-24

16. Räsänen HT, Manninen HI, Vanninen RL, et al. Mild carotid artery atherosclerosis: assessment by 3-dimensional time-of-flight magnetic resonance angiography, with reference to intravascular ultrasound imaging and contrast angiography. Stroke 1999;30:827-33

17. Nishimura RA, Edwards WD, Warnes CA, et al. Intravascular ultrasound imaging: in vitro validation and pathologic correlation. J Am Coll Cardiol 1990;16:145-54

18. Manninen HI, Räsänen H, Vanninen RL, et al. Human carotid arteries: correlation of intravascular US with angiographic and histopathologic findings. Radiology 1998;206:65-74

19. Irshad K, Reid DB, Miller PH, et al. Early clinical experience with color threedimensional intravascular ultrasound in peripheral interventions. J Endovasc Ther 2001;8:329-38

20. Rasheed Q, Dhawale PJ, Anderson J, et al. Intracoronary ultrasound-defined plaque composition: computer-aided plaque characterization and correlation with histologic samples obtained during directional coronary atherectomy. Am Heart J 1995;129:631-37

21. Potkin $\mathrm{BN}$, Bartorelli $\mathrm{AL}, \mathrm{Gessert} \mathrm{JM}$, et al. Coronary artery imaging with intravascular high-frequency ultrasound. Circulation 1990;81:1575-85

22. Schaar JA, Mastik F, Regar E, et al. Current diagnostic modalities for vulnerable plaque detection. Curr Pharm Des 2007;13:995-1001

23. Hiro T, Leung CY, Russo RJ, et al. Variability of a three-layered appearance in intravascular ultrasound coronary images: a comparison of morphometric measurements with four intravascular ultrasound systems. Am J Card Imaging 1996;10:219-27

24. Stary HC, Chandler AB, Dinsmore RE, et al. A definition of advanced types of atherosclerotic lesions and a histological classification of atherosclerosis: a report from the Committee on Vascular Lesions of the Council on Arteriosclerosis, American Heart Association. Arterioscler Thromb Vasc Biol 1995;15: 1512-31

25. Davies MJ, Thomas A. Thrombosis and acute coronary-artery lesions in sudden cardiac ischemic death. N Engl J Med 1984;310:1137-40

26. Levin DC, Fallon JT. Significance of the angiographic morphology of localized coronary stenoses: histopathologic correlations. Circulation 1982;66:316-20

27. Beach KW, Hatsukami T, Detmer PR, et al. Carotid artery intraplaque hemorrhage and stenotic velocity. Stroke 1993;24:314-19

28. Fryer JA, Myers PC, Appleberg M. Carotid intraplaque hemorrhage: the significance of neovascularity. J Vasc Surg 1987;6:341-49

29. von Maravic C, Kessler C, von Maravic M, et al. Clinical relevance of intraplaque hemorrhage in the internal carotid artery. Eur J Surg 1991;157: 185-88

30. Yamagishi M, Terashima M, Awano K, et al. Morphology of vulnerable coronary plaque: insights from follow-up of patients examined by intravascular ultrasound before an acute coronary syndrome. J Am Coll Cardiol 2000;35: 106-11

31. Spagnoli LG, Mauriello A, Sangiorgi G, et al. Extracranial thrombotically active carotid plaque as a risk factor for ischemic stroke. JAMA 2004;292:1845-52

32. Virmani R, Kolodgie FD, Burke AP, et al. Atherosclerotic plaque progression and vulnerability to rupture: angiogenesis as a source of intraplaque hemorrhage. Arterioscler Thromb Vasc Biol 2005;25:2054-61. Epub 2005 Jul 21

33. Kuchulakanti P, Rha SW, Cheneau E, et al. Identification of "vulnerable plaque" using virtual histology in angiographically benign looking lesion of proximal left anterior descending artery. Cardiovasc Radiat Med 2003;4: 225-27

34. Virmani R, Kolodgie FD, Burke AP, et al. Lessons from sudden coronary death: a comprehensive morphological classification scheme for atherosclerotic lesions. Arterioscler Thromb Vasc Biol 2000;20:1262-75

35. Sabetai, MM, Tegos TJ, Nicolaides AN, et al. Hemispheric symptoms and carotid plaque echomorphology. J Vasc Surg 2000;31(1 pt 1):39-49

36. Tegos TJ, Sohail M, Sabetai MM, et al. Echomorphologic and histopathologic characteristics of unstable carotid plaques. AJNR Am J Neuroradiol 2000;21: 1937-44

37. Verheye S, De Meyer GR, Van Langenhove G, et al. In vivo temperature heterogeneity of atherosclerotic plaques is determined by plaque composition. Circulation 2002;105:1596-601

38. Irshad K, Millar S, Velu R, et al. Virtual histology intravascular ultrasound in carotid interventions. J Endovasc Ther 2007;14:198-207

39. Naghavi M, Libby P, Falk E, et al. From vulnerable plaque to vulnerable patient: a call for new definitions and risk assessment strategies. Circulation 2003;108(pt 1):1664-72

40. Virmani R, Burke AP, Kolodgie FD, et al. Pathology of the thin-cap fibroatheroma: a type of vulnerable plaque. J Interv Cardiol 2003;16:267-72

41. Fujii K, Kobayashi Y, Mintz GS, et al. Intravascular ultrasound assessment of 
ulcerated ruptured plaques: a comparison of culprit and nonculprit lesions of patients with acute coronary syndromes and lesions in patients without acute coronary syndromes. Circulation 2003;108:2473-78. Epub 2003 Nov 10

42. Fisher CM, Ojemann R. A clinico-pathologic study of carotid endarterectomy plaques. Rev Neurol (Paris) 1986;142:573-89

43. Streifler JY, Eliasziw M, Fox AJ, et al. Angiographic detection of carotid plaque ulceration: comparison with surgical observations in a multicenter studyNorth American Symptomatic Carotid Endarterectomy Trial. Stroke 1994;25:1130-32

44. Fürst H, Hartl WH, Jansen I, et al. Color-flow Doppler sonography in the identification of ulcerative plaques in patients with high-grade carotid artery stenosis. AJNR Am J Neuroradiol 1992;13:1581-87

45. Kostamaa H, Donovan J, Kasaoka S, et al. Calcified plaque cross-sectional area in human arteries: correlation between intravascular ultrasound and undecalcified histology. Am Heart J 1999;137:482-88

46. Di Mario C, The SH, Madretsma S, et al. Detection and characterization of vascular lesions by intravascular ultrasound: an in vitro study correlated with histology. J Am Soc Echocardiogr 1992;5:135-46

47. Sechtem, U, Arnold G, Keweloh T, et al. In vitro diagnosis of coronary plaque morphology with intravascular ultrasound: comparison with histopathologic findings [in German]. Z Kardiol 1993;82:618-27

48. Friedrich GJ, Moes NY, Mühlberger VA, et al. Detection of intralesional calcium by intracoronary ultrasound depends on the histologic pattern. Am Heart J 1994;128:435-41

49. Frimerman A, Miller HI, Hallman M, et al. Intravascular ultrasound characterization of thrombi of different composition. Am J Cardiol 1994;73:1053-57

50. Lendon CL, Davies MJ, Born GV, et al. Atherosclerotic plaque caps are locally weakened when macrophages density is increased. Atherosclerosis 1991;87: $87-90$

51. Falk E. Stable versus unstable atherosclerosis: clinical aspects. Am Heart J 1999;138(5 pt 2):S421-25

52. Kimura BJ, Bhargava V, DeMaria AN. Value and limitations of intravascular ultrasound imaging in characterizing coronary atherosclerotic plaque. Am Heart J 1995;130:386-96

53. Glagov S, Weisenberg E, Zarins CK, et al. Compensatory enlargement of human atherosclerotic coronary arteries. N Engl J Med 1987;316:1371-75

54. Nissen SE, Yock P. Intravascular ultrasound: novel pathophysiological insights and current clinical applications. Circulation 2001;103:604-16

55. Schoenhagen P, Ziada KM, Kapadia SR, et al. Extent and direction of arterial remodeling in stable versus unstable coronary syndromes: an intravascular ultrasound study. Circulation 2000;101:598-603

56. Varnava AM, Mills PG, Davies MJ. Relationship between coronary artery remodeling and plaque vulnerability. Circulation 2002;105:939-43

57. Finet G, Maurincomme E, Tabib A, et al. Artifacts in intravascular ultrasound imaging: analyses and implications. Ultrasound Med Biol 1993;19:533-47

58. Jensen LO, Thayssen P, Pedersen KE, et al. Regression of coronary atherosclerosis by simvastatin: a serial intravascular ultrasound study. Circulation 2004;110:265-70. Epub 2004 Jul 6

59. Gupta R, Bhatt A, Kassab M, et al. Intravascular ultrasound to assess extracranial vertebral artery restenosis: case report. J Neuroimaging 2008;18:336-39. Epub 2008 May 19

60. Reid DB, Douglas M, Diethrich EB. The clinical value of three-dimensional intravascular ultrasound imaging. J Endovasc Surg 1995;2:356-64

61. White RA, Scoccianti $M$, Back $M$, et al. Innovations in vascular imaging: arteriography, three-dimensional CT scans, and two- and three-dimensional intravascular ultrasound evaluation of an abdominal aortic aneurysm. Ann Vasc Surg 1994;8:285-89

62. Irshad K, Rahaman N, Bain D, et al. The role of intravascular ultrasound in carotid angioplasty and stenting. In: Henry M, ed. Textbook of Peripheral Vascular Interventions. London, UK: Martin Dunitz; 2004

63. Okubo M, Kawasaki M, Ishihara Y, et al. Tissue characterization of coronary plaques: comparison of integrated backscatter intravascular ultrasound with virtual histology intravascular ultrasound. Circ J 2008;72:1631-39. Epub 2008 Aug 28

64. Vince DG, Davies SC. Peripheral application of intravascular ultrasound virtual histology. Semin Vasc Surg 2004;17:119-25

65. Nair A, Kuban BD, Obuchowski N, et al. Assessing spectral algorithms to predict atherosclerotic plaque composition with normalized and raw intravascular ultrasound data. Ultrasound Med Biol 2001;27:1319-31

66. Nair A, Kuban BD, Tuzcu EM, et al. Coronary plaque classification with intravascular ultrasound radiofrequency data analysis. Circulation 2002;106: $2200-06$

67. Diethrich EB, Pauliina Margolis M, Reid DB, et al. Virtual histology intravascular ultrasound assessment of carotid artery disease: the Carotid Artery Plaque Virtual Histology Evaluation (CAPITAL) study. J Endovasc Ther 2007;14:676-86

68. Picano E, Landini L, Distante A, et al. Angle dependence of ultrasonic backscatter in arterial tissues: a study in vitro. Circulation 1985;72:572-76

69. Hiro T, Leung CY, Karimi H, et al. Angle dependence of intravascular ultra- sound imaging and its feasibility in tissue characterization of human atherosclerotic tissue. Am Heart J 1999; 137:476-81

70. Cachard C, Finet G, Bouakaz A, et al. Ultrasound contrast agent in intravascular echography: an in vitro study. Ultrasound Med Biol 1997;23:705-717

71. Lanza GM, Wallace KD, Fischer SE, et al. High-frequency ultrasonic detection of thrombi with a targeted contrast system. Ultrasound Med Biol 1997;23: $863-70$

72. Moulton KS, Vakili K, Zurakowski D, et al. Inhibition of plaque neovascularization reduces macrophage accumulation and progression of advanced atherosclerosis. Proc Natl Acad Sci U S A 2003;100:4736-41. Epub 2003 Apr 7

73. Moreno PR, Purushothaman KR, Fuster V, et al. Plaque neovascularization is increased in ruptured atherosclerotic lesions of human aorta: implications for plaque vulnerability. Circulation 2004;110:2032-38. Epub 2004 Sep 27

74. Moreno PR, Purushothaman KR, Fuster V, et al. Intimomedial interface dam age and adventitial inflammation is increased beneath disrupted atherosclerosis in the aorta: implications for plaque vulnerability. Circulation 2002;105: 2504-11

75. Pasterkamp G, Schoneveld AH, van der Wal AC, et al. Relation of arterial geometry to luminal narrowing and histologic markers for plaque vulnerability: the remodeling paradox. J Am Coll Cardiol 1998;32:655-62

76. Vavuranakis M, Papaioannou TG, Kakadiaris IA, et al. Detection of perivascular blood flow in vivo by contrast-enhanced intracoronary ultrasonography and image analysis: an animal study. Clin Exp Pharmacol Physiol 2007;34: $1319-23$

77. Feinstein SB. The powerful microbubble: from bench to bedside, from intravascular indicator to therapeutic delivery system, and beyond. Am J Physiol Heart Circ Physiol 2004;287:H450 -57

78. Hamilton AJ, Huang SL, Warnick D, et al. Intravascular ultrasound molecular imaging of atheroma components in vivo. J Am Coll Cardiol 2004;43:453-60

79. Vavuranakis M, Kakadiaris IA, O'Malley SM, et al. A new method for assessment of plaque vulnerability based on vasa vasorum imaging, by using contrast-enhanced intravascular ultrasound and differential image analysis. Int J Cardiol 2008;130:23-29. Epub 2008 Feb 20

80. Galili O, Herrmann J, Woodrum J, et al. Adventitial vasa vasorum heterogeneity among different vascular beds. J Vasc Surg 2004;40:529-35

81. Heistad DD, Marcus ML, Larsen GE, et al. Role of vasa vasorum in nourishment of the aortic wall. Am J Physiol 1981;240:H781-87

82. Williams JK, Armstrong ML, Heistad DD. Vasa vasorum in atherosclerotic coronary arteries: responses to vasoactive stimuli and regression of atherosclerosis. Circ Res 1988;62:515-23

83. Tresukosol D, Wongpraparut N, Lirdvilai T. The value of intravascular ultrasound-facilitated internal carotid artery stenting in a patient with heavily calcified and ambiguous common carotid artery stenosis. I Invasive Cardio 2007;19:E203-06

84. Eikelboom BC, Riles TR, Mintzer R, et al. Inaccuracy of angiography in the diagnosis of carotid ulceration. Stroke 1983;14:882-85

85. Hermiller JB, Buller CE, Tenaglia AN, et al. Unrecognized left main coronary artery disease in patients undergoing interventional procedures. $\mathrm{Am} \mathrm{J} \mathrm{Car}$ diol 1993;71:173-76

86. Weissman NJCM, Mintz GS, Laird JR Jr, et al. Carotid artery intravascular ultrasound: safety and morphologic observations during carotid stenting in 102 patients. J Am Coll Cardiol 2000;35(2 supple 1):10A

87. Yoon WK, Kim YW, Kim SD, et al. Intravascular ultrasonography-guided stent angioplasty of an extracranial vertebral artery dissection. J Neurosurg 2008;109:1113-18

88. Takayama K, Taoka T, Nakagawa H, et al. Successful percutaneous transluminal angioplasty and stenting for symptomatic intracranial vertebral artery stenosis using intravascular ultrasound virtual histology. Radiat $\mathrm{Med}$ 2007;25:243-46. Epub 2007 Jun 27

89. Nissen SE, Tsunoda T, Tuzcu EM, et al. Effect of recombinant ApoA-I Milano on coronary atherosclerosis in patients with acute coronary syndromes: a randomized controlled trial. JAMA 2003;290:2292-300

90. Matsuzaki M, Hiramori K, Imaizumi T, et al. Intravascular ultrasound evaluation of coronary plaque regression by low density lipoprotein-apheresis in familial hypercholesterolemia: the Low Density Lipoprotein-Apheresis Coronary Morphology and Reserve Trial (LACMART). J Am Coll Cardio 2002;40:220-27

91. Petronio AS, Amoroso G, Limbiuno U, et al. Simvastatin does not inhibit intimal hyperplasia and restenosis but promotes plaque regression in normocholesterolemic patients undergoing coronary stenting: a randomized study with intravascular ultrasound. Am Heart J 2005;149:520-26

92. Okazaki S, Yokoyama T, Miyauchi K, et al. Early statin treatment in patients with acute coronary syndrome: demonstration of the beneficial effect on atherosclerotic lesions by serial volumetric intravascular ultrasound analysis during half a year after coronary event-the ESTABLISH Study. Circulation 2004;110:1061-68. Epub 2004 Aug 23

93. Sipahi I, Tuzcu EM. Candidate mechanisms for regression of coronary ath erosclerosis with high-dose statins: insight from intravascular ultrasonog raphy trials. Am J Cardiovasc Drugs 2008;8:365-371

94. Nicholls SJ, Tuzcu EM, Brennan DM, et al. Cholesteryl ester transfer protein 
inhibition, high-density lipoprotein raising, and progression of coronary atherosclerosis: insights from ILLUSTRATE (Investigation of Lipid Level Management Using Coronary Ultrasound to Assess Reduction of Atherosclerosis by CETP Inhibition and HDL Elevation). Circulation 2008;118: 2506-14. Epub 2008 Nov 24

95. Davidson MH, Dembowski E, Atherosclerosis surrogate imaging trials come of age: for better or for worse? Curr Cardiol Rep 2008;10:521-25

96. Thompson JB, Blaha M, Resar JR, et al. Strategies to reverse atherosclerosis: an imaging perspective. Curr Treat Options Cardiovasc Med 2008;10:283-93

97. Kastelein JJ, de Groot E. Ultrasound imaging techniques for the evaluation of cardiovascular therapies. Eur Heart J 2008;29:849-58

98. Nash DT. Use of vascular ultrasound in clinical trials to evaluate new cardiovascular therapies. J Natl Med Assoc 2008;100:222-29

99. Nishioka H, Shimada K, Kataoka T, et al. Impact of HMG-CoA reductase inhibitors for non-treated coronary segments. Osaka City Med J 2004;50: $61-68$

100. Ibañez B, Badimon JJ, Garcia MJ. Diagnosis of atherosclerosis by imaging. Am J Med 2009;122(1 suppl):S15-25

101. Iwata A, Miura S, Imaizumi S, et al. Measurement of atherosclerotic plaque volume in hyperlipidemic rabbit aorta by intravascular ultrasound. J Cardiol 2007;50:229-34

102. Arora S, Nicholls SJ. Atherosclerotic plaque reduction: Blood pressure, dyslipidemia, atherothrombosis. Drugs Today (Barc) 2008;44:711-18

103. Wierzbicki A. Lipid-altering therapies and the progression of atherosclerotic disease. Cardiovasc Intervent Radiol 2007;30:155-160

104. Clementi F, Di Luozzo M, Mango R, et al. Regression and shift in composition of coronary atherosclerotic plaques by pioglitazone: insight from an intravascular ultrasound analysis. J Cardiovasc Med (Hagerstown) 2009;10:231-37

105. Nissen SE, Nicholls SJ, Sipahi I, et al. Effect of very high-intensity statin therapy on regression of coronary atherosclerosis: the ASTEROID trial. JAMA 2006;295:1556-65

106. Crouse JR 3rd, Raichlen JS, Riley WA, et al. Effect of rosuvastatin on progression of carotid intima-media thickness in low-risk individuals with subclinical atherosclerosis: the METEOR Trial. JAMA 2007;297:1344-53. Epub 2007 Mar 25

107. Nissen SE, Tuzcu EM, Schoenhagen P, et al. Effect of intensive compared with moderate lipid-lowering therapy on progression of coronary atherosclerosis: a randomized controlled trial. JAMA 2004;291:1071-80

108. Nissen SE, Nicholls SJ, Wolski K, et al. Effect of rimonabant on progression of atherosclerosis in patients with abdominal obesity and coronary artery disease: the STRADIVARIUS randomized controlled trial. JAMA 2008;299: 1547-60

109. Kushner, P. Can intensive statin therapy halt the progression of atherosclerosis? Recent evidence and potential implications for patient management. Prog Cardiovasc Nurs 2007;22:207-213

110. Ratner RE, Cannon CP, Gerstein HC, for the APPROACH Study Group. Assessment on the Prevention of Progression by Rosiglitazone on Atherosclerosis in Diabetes Patients with Cardiovascular History (APPROACH): study design and baseline characteristics. Am Heart J2008;156:1074-79. Epub 2008 Oct 11

111. Diethrich EB, Ndiaye M, Reid DB. Stenting in the carotid artery: initial experience in 110 patients. J Endovasc Surg 1996;3:42-62

112. Aviram G, Shmilovich H, Finkelstein A, et al. Coronary ostium-straight tube or funnel-shaped? A computerized tomographic coronary angiography study. Acute Card Care 2006;8:224-28

113. Chetcuti SJ, Moscucci M. Double-wire technique for access into a protruding aorto-ostial stent for treatment of in-stent restenosis. Catheter Cardiovasc Interv 2004;62:214-17

114. Demer LL. Effect of calcification on in vivo mechanical response of rabbit arteries to balloon dilation. Circulation 1991;83:2083-93

115. Reid DB, Irshad K, Miller S, et al. Endovascular significance of the external carotid artery in the treatment of cerebrovascular insufficiency. J Endovasc Ther 2004;11:727-33

116. Oemrawsingh PV, Mintz GS, Schalij MJ, et al. Intravascular ultrasound guidance improves angiographic and clinical outcome of stent implantation for long coronary artery stenoses: final results of a randomized comparison with angiographic guidance (TULIP Study). Circulation 2003;107:62-67

117. Grube E, Sievert H, Hauptmann KE, et al. Novel drug eluting stent system for customised treatment of coronary lesions: CUSTOM I feasibility trial 24 month results. EuroIntervention 2008;4:71-76

118. Wehman JC, Holmes DR Jr, Ecker RD, et al. Intravascular ultrasound identification of intraluminal embolic plaque material during carotid angioplasty with stenting. Catheter Cardiovasc Interv 2006;68:853-57

119. Meyers PM, Schumacher HC, Gray WA, et al. Intravascular ultrasound of symptomatic intracranial stenosis demonstrates atherosclerotic plaque with intraplaque hemorrhage: a case report. J Neuroimaging 2009;19:266-70. Epub 2008 Oct 24

120. Kaneda H, Ikeno F, Lyons J, et al. Long-term histopathologic and IVUS evaluations of a novel coiled sheet stent in porcine carotid arteries. Cardiovasc Intervent Radiol 2006;9:413-19

121. Mintz GS, Popma JJ, Pichard AD, et al. Intravascular ultrasound predictors of restenosis after percutaneous transcatheter coronary revascularization. I Am Coll Cardiol 1996;27:1678-87

122. Clark DJ, Lessio S, O'Donoghue M, et al. Mechanisms and predictors of carotid artery stent restenosis: a serial intravascular ultrasound study. $J \mathrm{Am}$ Coll Cardiol 2006;47:2390-96. Epub 2006 May 30

123. Kasaoka S, Tobis JM, Akiyama T, et al. Angiographic and intravascular ultrasound predictors of in-stent restenosis. J Am Coll Cardiol 1998;32:1630-35

124. Schiele F, Meneveav N, Vuillemenot A, et al. Impact of intravascular ultrasound guidance in stent deployment on 6-month restenosis rate: a multicenter, randomized study comparing two strategies-with and without intravascular ultrasound guidance. RESIST Study Group. REStenosis after Ivus guided STenting. J Am Coll Cardiol 1998;32:320-28

125. Rosenfield K, Schainfeld R, Pieczek A, et al. Restenosis of endovascular stents from stent compression. J Am Coll Cardiol 1997;29:328-38

126. Painter JA, Mintz GS, Wong SC, et al. Serial intravascular ultrasound studie fail to show evidence of chronic Palmaz-Schatz stent recoil. Am J Cardio 1995;75:398-400

127. Elson JD, Becker GJ, Wholey $\mathrm{MH}$, et al. Vena caval and central venous stenoses: management with Palmaz balloon-expandable intraluminal stents. J Vasc Interv Radiol 1991;2:215-23

128. Bjarnason H, Hunter DW, Crain MR, et al. Collapse of a Palmaz stent in the subclavian vein. AJR Am J Roentgenol 1993;160:1123-24

129. Bates MC, Almehmi A. Carotid stenting for symptomatic radiation-induced arteritis complicated by recurrent aneurysm formation. Catheter Cardiovasc Interv 2004;63:507-11

130. Schwarzacher SP, Metz JA, Yock PG, et al. Vessel tearing at the edge of intracoronary stents detected with intravascular ultrasound imaging. Cathet Cardiovasc Diagn 1997;40:152-55

131. Metz JA, Mooney MR, Walter PD, et al. Significance of edge tears in coronary stenting: initial observations from the STRUT (Stent Treatment Region assessed by Ultrasound Tomography) registry (abstr 2606). Circulation 1995; 92(Suppl I):I-S46

132. Tsuura M, Terada T, Nakai K, et al. Endovascular stent placement for cervical internal carotid artery aneurysm causing cerebral embolism: usefulness of neuroradiological evaluation. Acta Neurochir (Wien) 1999;141:503-07

133. Manninen HI, Koivisto T, Saari T, et al. Dissecting aneurysms of all four cervicocranial arteries in fibromuscular dysplasia: treatment with self-expanding endovascular stents, coil embolization, and surgical ligation. AJNR Am J Neuroradiol 1997;18:1216-20

134. Shindo A, Kawanishi M, Masada T, et al. Usefulness of intravascular ultrasound in embolization of dural arteriovenous fistula: a case report [in Japanese]. No Shinkei Geka 2003;31:1323-29

135. Gasparis AP, Kokkosis A, Labropoulos N, et al. Venous outflow obstruction with retroperitoneal Kaposi's sarcoma and treatment with inferior vena cava stenting. Vasc Endovascular Surg 2009;43:295-300. Epub 2009 Jan 8

136. Schiro BJ, Wholey MH. The expanding indications for virtual histology in travascular ultrasound for plaque analysis prior to carotid stenting. J Car diovasc Surg (Torino) 2008;49:729-36

137. Reimers B, Corvaja N, Moshiri S, et al. Cerebral protection with filter devices during carotid artery stenting. Circulation 2001;104:12-15

138. Macdonald S, McKevitt F, Venables GS, et al. Neurological outcomes after carotid stenting protected with the NeuroShield filter compared to unprotected stenting. J Endovasc Ther 2002;9:777-85

139. Henry M, Polydorou A, Henry I, et al. Carotid angioplasty under cerebra protection with the PercuSurge GuardWire System. Catheter Cardiovasc Interv 2004;61:293-305

140. Bosiers M, Peeters P, Verbist J, et al. Belgian experience with FilterWire EX in the prevention of embolic events during carotid stenting. J Endovasc Ther 2003;10:695-701

141. Al-Mubarak N, Colombo A, Gaines PA, et al. Multicenter evaluation of carotid artery stenting with a filter protection system. J Am Coll Cardiol 2002;39:841-46

142. Castriota F, Cremonesi A, Manetti R, et al. Impact of cerebral protection devices on early outcome of carotid stenting. J Endovasc Ther 2002;9:786-92

143. Parodi JC, La Mura R, Ferreira LM, et al. Initial evaluation of carotid angioplasty and stenting with three different cerebral protection devices. J Vasc Surg 2000;32:1127-36 